P.R. Mohapatra and D.T. Hari also point out that we do not consider the benefits of using intermittent therapy. Again, the primary objective of our study was to consider gains that could be made by switching to a WHO-supported standardised regimen, one in which daily therapy is recommended wherever feasible [2].

\section{O. Oxlade and D. Menzies}

Montreal Chest Institute, Respiratory Epidemiology Unit, Montreal, Quebec, Canada.

Correspondence: D. Menzies, Respiratory Epidemiology Unit, Montreal Chest Institute, 3650 St Urbain, Room K1.24,
Montreal, Quebec, Canada, H2X 2P4. E-mail: dick.menzies@ mcgill.ca

Statement of Interest: None declared

\section{REFERENCES}

1 Oxlade $\mathrm{O}$, Schwartzman $\mathrm{K}$, Pai M, et al. Predicting outcomes and drug resistance with standardised treatment of active tuberculosis. Eur Respir J 2010; 36: 870-877.

2 World Health Organization. Treatment of Tuberculosis Guidelines. 4th Edn. Report No. WHO/HTM/TB/2009.420. Geneva, World Health Organization, 2010.

\title{
Estimated population prevalence of obstructive sleep apnoea in a community of German third graders
}

\section{To the Editors:}

We read with interest the article by URSCHITZ et al. [1] which estimated the population prevalence of obstructive sleep apnoea (OSA) in an urban community of German third graders. This article highlights the fact that OSA is one of the most common chronic respiratory diseases in childhood and requires more attention from paediatric health services and clinicians. However, we are concerned that the methods employed in the study to diagnose OSA were suboptimal.

The authors correctly state that full sleep laboratory based polysomnography is the gold standard for the diagnosis of OSA in children. However, for the purposes of their study, abbreviated home polysomnography (HPSG) without electroencephalography was utilised for a final diagnosis of OSA. This was not referenced to the gold standard in this study.

The most recent American Academy of Sleep Medicine manual on scoring of sleep and sleep-related events emphasises the need to record and score not only respiratory events, but also arousals throughout a polysomnography [2]. The manual states that if hypopnoeas are to be scored (and form part of the apnoea/ hypopnoea index), they must be followed by either arousal or desaturation. The abbreviated HPSG used in this study does not have the ability to detect respiratory events that lead to arousal. On this basis, we feel that the authors may have underestimated the prevalence of OSA in their study population.

\section{Finn and P. McNally}

Dept of Respiratory Medicine, Our Lady's Children's Hospital, Crumlin, Dublin 12, Ireland.

Correspondence: P. McNally, Dept of Respiratory Medicine, Our Lady's Children's Hospital, Crumlin, Dublin 12, Ireland. E-mail: paul.mcnally@olchc.ie
Statement of Interest: None declared.

\section{REFERENCES}

1 Urschitz MS, Brockmann PE, Schauld M, et al. Population prevalence of obstructive sleep apnoea in a community of German third graders. Eur Respir J 2010; 36: 556-568.

2 Iber C., Ancoli-Israel S., Chesson AL., et al., eds. The AASM Manual for the Scoring of Sleep and Associated Events: Rules, Terminology and Technical Specifications. Westchester, American Academy of Sleep Medicine, 2007.

DOI: $10.1183 / 09031936.00185610$

From the authors:

We thank D. Finn and P. McNally for their comments on our recent publication in the European Respiratory Journal [1].

We agree that full sleep laboratory-based polysomnography (PSG) including electroencephalography (EEG) may have a higher sensitivity in detecting obstructive sleep apnoea (OSA) in children, and that its use may have led to a higher estimate for the prevalence of OSA in our study. However, our study was designed in 2000, long before the relevant guideline of the American Academy of Sleep Medicine (AASM) was published [2]. At that time, there was widespread debate about the way in which hypopnoea and arousals should be scored and about the significance of these events in children. Many authors used definitions for hypopnoea that were based solely on a reduction in airflow or on both a reduction in airflow and desaturation. In a study by MCNAMARA et al. [3], only 38-39\% of respiratory events (including hypopnoea) were followed by cortical arousal, while all hypopnoeas were followed by a desaturation of $\geqslant 4 \%$. In addition, the occurrence of a cortical arousal following respiratory events depended on age. In contrast to the current AASM guideline, the minimal required duration for a cortical 
arousal was $1 \mathrm{~s}$ (actually $3 \mathrm{~s}$ in the AASM guideline). It can be assumed that increasing the minimal required duration to $3 \mathrm{~s}$ would lead to a further reduction in the proportion of hypopnoeas that were terminated with a cortical arousal. This was later confirmed by a study showing that only $51 \%$ of hypopnoeas were terminated by cortical arousal in children [4]. In a study on normative data for hypopnoea in children, WiTMANS et al. [5] reported that only one out of six children with hypopnoeas had their hypopnoea terminated with cortical arousals. Because of this lack of clarity and the problems with establishing EEG recordings at home, other large-scale epidemiological studies, such as the Children's Sleep and Health Study [6], also used abbreviated PSG without EEG at that time.

Despite this, we agree that nowadays epidemiological studies should use full PSG with EEG to identify OSA in children, particularly because appropriate devices are now available.

In conclusion, it remains to be shown if and how another definition for hypopnoea that incorporates cortical arousal criteria would have changed our estimate of the prevalence of OSA in children.

\section{M.S. Urschitz* P.E. Brockmann*,\#, M. Schlaud ${ }^{\top}$ and C.F. Poets*}

*Dept of Neonatology, University Children's Hospital, Tuebingen, and "Dept of Epidemiology and Health Reporting, Robert Koch Institute, Berlin, Germany. ${ }^{\#}$ Dept of Paediatrics, Pontificia Universidad Catolica de Chile, Santiago de Chile, Chile.
Correspondence: M.S. Urschitz, Working Group on Paediatric Sleep Medicine, Dept of Neonatology, University Children's Hospital Tuebingen, Calwerstr. 7, 72076 Tuebingen, Germany. E-mail: michael.urschitz@med.uni-tuebingen.de

Statement of Interest: None declared.

\section{REFERENCES}

1 Urschitz MS, Brockmann PE, Schlaud M, et al. Population prevalence of obstructive sleep apnoea in a community of German third graders. Eur Respir J 2010; 36: 556-568.

2 Iber C, Ancoli-Israel S, Chesson A, et al. The AASM Manual for the Scoring of Sleep and Associated Event: Rules, Terminology and Technical Specifications. 1st Edn. Westchester, American Academy of Sleep Medicine, 2007.

3 McNamara F, Issa FG, Sullivan CE. Arousal pattern following central and obstructive breathing abnormalities in infants and children. J Appl Physiol 1996; 81: 2651-2657.

4 Katz ES, Lutz J, Black C, et al. Pulse transit time as a measure of arousal and respiratory effort in children with sleep-disordered breathing. Pediatr Res 2003; 53: 580-588.

5 Witmans MB, Keens TG, Davidson Ward SL, et al. Obstructive hypopneas in children and adolescents: normal values. Am J Respir Crit Care Med 2003; 168: 1540.

6 Rosen CL, Larkin EK, Kirchner HL, et al. Prevalence and risk factors for sleep-disordered breathing in 8- to 11-year-old children: association with race and prematurity. J Pediatr 2003; 142: 383-389.

DOI: $10.1183 / 09031936.00202010$ 